\title{
Topographic effects on frequency-size distribution of landslides triggered by the Hokkaido Eastern Iburi Earthquake in 2018
}

Mio Kasai* ${ }^{*}$ and Takashi Yamada

\begin{abstract}
This study examined the frequency-size distribution of 6117 landslides spread over $440 \mathrm{~km}^{2}$ in Iburi Subprefecture, Hokkaido, Japan, induced by the Hokkaido Eastern Iburi Earthquake $\left(M_{w} 6.6\right)$ on September 6, 2018. The study area is characterized by gently undulating terrain that is finely dissected by shallow streams and covered predominantly by layers of volcanic products with high water content. Most of the landslides were shallow landslides, and their slip surfaces often formed in a layer of volcanic soil called the "Ta-d," deposited at $9000 \mathrm{ybp}$. Low ridges separating small catchments allowed individual landslides to coalesce in many locations. The average size of landslides was $7160 \mathrm{~m}^{2}$. Landslide size tended to increase with slope angle up to $20^{\circ}$ to $25^{\circ}$ and then decrease with further increase of slope angle. About half of the landslides occurred in a feature with both concave planform and profile curvature, and their average size was $8720 \mathrm{~m}^{2}$. In contrast, $17 \%$ of the total landslides occurred in the case of both curvatures being convex, and their average size was $5190 \mathrm{~m}^{2}$. The results indicated that the accumulation of saturated soil in concave features provided more opportunities for landslides of large sizes. The frequency-size distribution of the landslides presented high rollover, $5.0 \times 10^{-3} \mathrm{~km}^{2}$, but the exponent of power law decay for medium to large landslides, -2.46 , was not largely different from those of studies in other locations. Compared with other seismically caused examples, the landslides triggered by the Hokkaido Eastern Iburi Earthquake can be characterized as more clustered, more numerous, and larger in size for the moment magnitude of the earthquake. Conversely, the magnitude scale for the landslide event estimated from the total landslide area was equivalent to that of a region struck by an earthquake of $M_{w}=7.0$ to 7.4. This study demonstrated that gently undulating regions can produce unexpectedly large and frequent landslides when struck by an intense earthquake, and when soil layers vulnerable to ground shaking cover the ground.
\end{abstract}

Keywords: Frequency-size distribution, Hokkaido Eastern Iburi Earthquake, Shallow landslides, Slope angle, Slope curvature, Volcanic soil

\section{Introduction}

Earthquakes can trigger numerous landslides, causing huge financial losses through damaged infrastructure and property, as well as human casualties. The total number, area, and volume of landslides tend to become larger as the moment magnitude of the causative earthquake

*Correspondence: kasaim@for.agr.hokudai.ac.jp

Research Faculty of Agriculture, Hokkaido University, Kita-9 Nishi-9, Kita-ku, Sapporo, Japan increases, whereas their type, such as shallow landslide, deep rotational slide, debris flow, earthflow, or rock avalanche, varies according to the geology and topography of the sites (Rodríguez et al. 1999; Keefer 2002). The probability-size distribution of landslides is typically universally similar; when landslides are small, the probability of landslide occurrence increases with size, but decreases after a size threshold, or 'rollover', is reached. This relationship follows a power law decay for medium to large landslides (Malamud et al. 2004; Van Den Eeckhaut et al. 
2007). Hence, determining the rollover and power law decay exponent for the region of interest is useful for hazard assessment because the frequency density, or possible number, of landslides of various sizes can be estimated by multiplying the probability by the total number of landslides, which is related to the moment magnitude of a potential earthquake (Keefer 1994).

Malamud et al. (2004) devised an inverse gamma equation that enabled them to represent the probability-size distribution of landslides from three locations. Although the landslide cases that they investigated were triggered by different types of events (earthquake, snowmelt, and rainfall), the equation indicated common features among them: the average size of landslides was $3.07 \times 10^{-3} \mathrm{~km}^{2}$, rollover occurred at the size of $4.0 \times 10^{-4} \mathrm{~km}^{2}$, and the exponent of power law decay for medium to large landslides was -2.3. Van Den Eeckhaut et al. (2007) also demonstrated an exponent within $-2.3 \pm 0.6$ based on both historical and event-triggered landslide inventories collected from around the world. However, their collection indicated that rollover can vary to a larger degree than the exponent. The factors determining these values are not entirely understood at present, although a series of studies has revealed some associations with slope processes. Pelletier et al. (1997) explained power law decay based on a threshold slope shear stress and indicated that the dynamics of soil moisture determine the size distribution of landslides. On the other hand, based on slope stability analyses, Frattini and Crosta (2013) demonstrated that soil cohesion controls rollover. After carrying out experiments using a vibrating sandbox, Katz and Aharonov (2006) concluded that two groups of natural landslides affect the distribution, i.e., shallow landslides within unconsolidated and homogeneous soil for small landslides and deeper slides of rock mass with a heterogeneous nature due to fractures, layers, or bedding for large landslides; they suggested that the size of shallow landslides is related to the depth of soil. However, both slope material properties and slope topography affect the probability-size distribution. Although high-elevation relief tends to produce larger landslides (Korup et al. 2007), Frattini and Crosta (2013) stated that the area of slopes is constricted between high ridges in deeply dissected landscapes, thereby limiting landslide size. Based on field observations and simulations of loess slides, Qiu et al. (2018) reported that slope length, rather than slope angle, is the major determinant of landslide size and rollover. However, these studies did not consider topographic effects on soil depth and groundwater accumulation, which indicate the sensitivity of a slope to ground shaking that works to increase pore water pressure and reduce slope material cohesion. Assuming that a concave feature is likely to collect more groundwater and accumulate deeper soil than a convex feature, and thus be at increased risk of landslide occurrence and increased landslide sizes, slope curvature should affect the frequency-size distribution of landslides. Similarly, slope angle should also be investigated from this point of view because steeper slopes cannot hold groundwater or slope materials for as long as gentler slopes, unless the materials are sufficiently coherent to remain on the slope.

In this study, the frequency-size distribution of landslides induced by the Hokkaido Eastern Iburi Earthquake (Mw 6.6) on September 6, 2018 and its association with slope angle and curvature were examined. The landscape is characterized by gently undulating terrain densely dissected by streams with low divides between catchments, and slope length is mostly limited (Fig. 1). Slopes are covered predominantly by layers of volcanic ash and pumice, in which most of the slip surfaces of landslides formed. Most of landslides observed after the earthquake were shallow landslides, but there were several deep-seated slides, including one that formed a landslide dam. At the end of this study, the size distribution of the landslides was compared with those induced by other seismic events, to highlight the distinctive topographic characteristics and soil properties and appraise the magnitude of this landslide event. The outcome raises concern regarding potential landslide disasters in regions covered with layers of soil with high water content, but this risk is rarely recognized because a large proportion of hillslopes are gentler than the angle of repose of the slope materials.

\section{Study area}

This study examined an area of $440 \mathrm{~km}^{2}$ in the Iburi Subprefecture, southern part of Hokkaido Island, affected by landslides triggered by the Hokkaido Eastern Iburi Earthquake (Fig. 1a). The epicenter of the earthquake was located at $42.686^{\circ} \mathrm{N}, 141.929^{\circ} \mathrm{E}$, the focus depth was $35.0 \mathrm{~km}$, and the modified Mercalli intensity scale in the area ranged from 7.5 to 9 (US Geological Survey [USGS]: https://earthquake.usgs.gov/earthquakes/eventpage/ us2000h8ty/executive\#pager). The peak ground acceleration around the area recorded by the National Research Institute for Earth Science and Disaster Resilience (NIED), Japan, was $1796 \mathrm{gal}$ at max (https://www.kyosh in.bosai.go.jp/kyoshin/topics/html20180906030750/ main_20180906030750.html), or $75.62 \% \mathrm{~g}$ as determined by the USGS (same website as above). Based on an analysis of soil stratigraphy and carbon dating by Tajika et al. (2016), part of the area was struck by an earthquake triggering landslides sometime between 4600 and $2500 \mathrm{ybp}$.

The landscape is characterized by gently undulating hills with elevations of 200 to $400 \mathrm{~m}$ that become steeper toward the east (Fig. 1). About $70 \%$ of the slopes in the area are lower than $30^{\circ}$, and about $60 \%$ of the landslides 


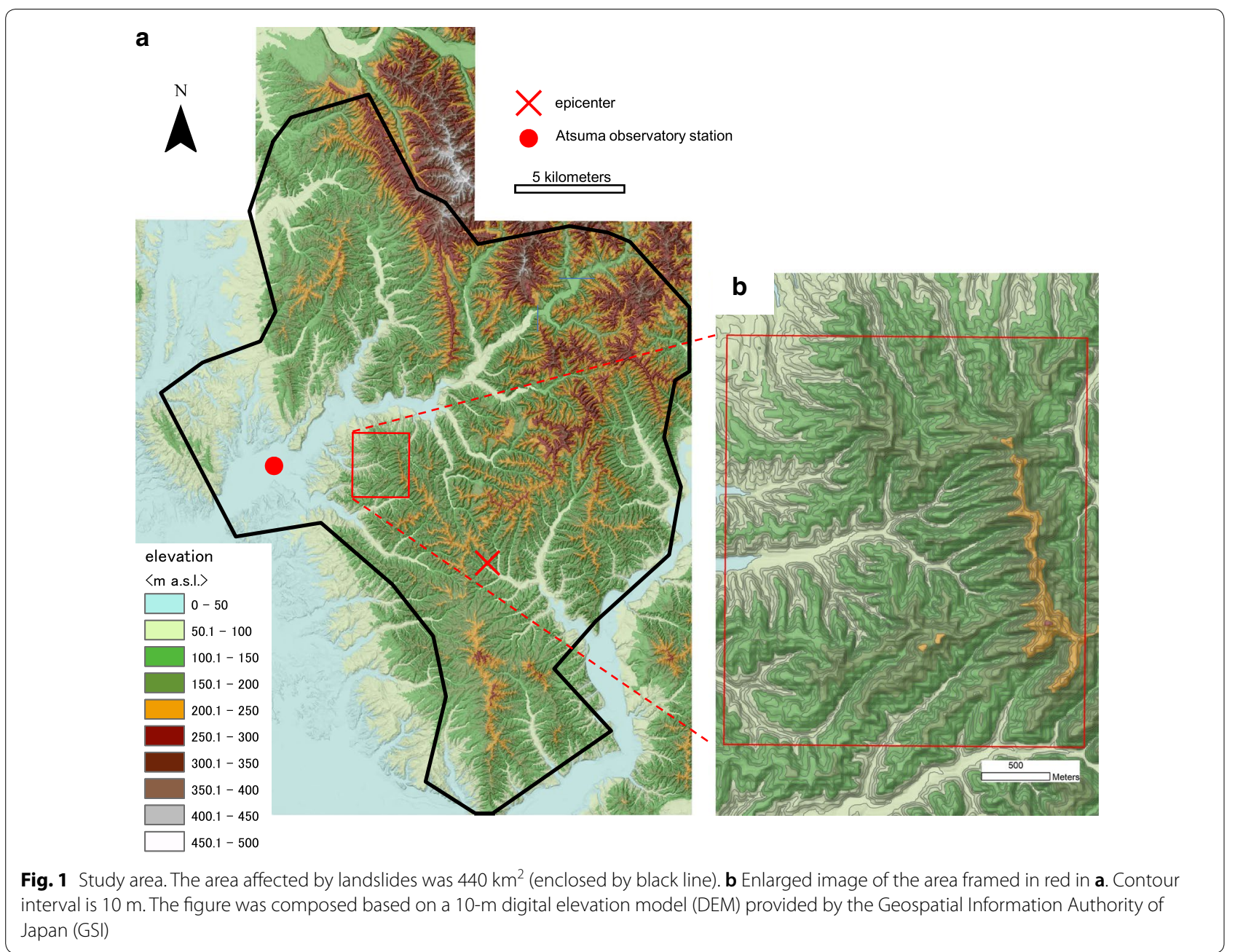

that occurred during the earthquake were on slopes of between $20^{\circ}$ and $30^{\circ}$ (Fig. 2). The ground is mostly covered by several layers of volcanic ash, pumice, and scoria, with alternations of andosols, underlain by Miocene to Pleistocene sedimentary rocks (Yanai 1989; Ozaki et al. 2014; Nakagawa et al. 2018). These volcanic products originated from the Kuttara, Shikotsu, Eniwa, and Tarumae volcanoes located 50 to $70 \mathrm{~km}$ southwest of the area.

Landslides induced by the earthquake spread toward the north-northwest direction from the epicenter, compatible with the strike of faults (Fig. 3), and were particularly clustered between 6 and $13 \mathrm{~km}$ from the epicenter (Figs. 3, 4). This is a rather unusual spatial pattern for seismically induced landslides, which generally concentrate around the epicenter (Keefer 2002). The reason for this unique pattern is presently unclear, but it may relate to the motion pattern of fault planes and the associated peak ground acceleration.

Most of the landslides observed in the area after the earthquake were shallow landslides, occurring on both

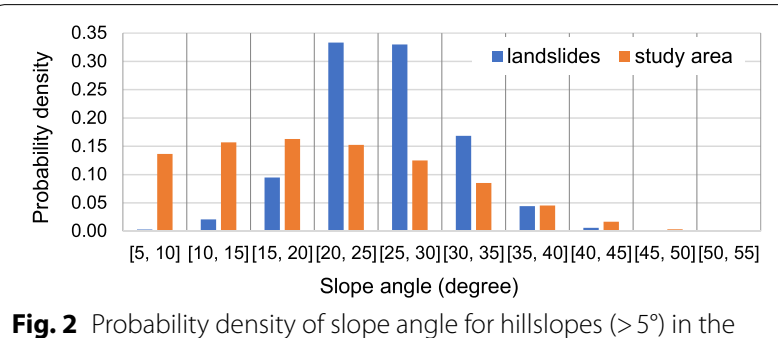

study area and landslides

concave and convex slopes. Low ridges separating small catchments allowed individual landslides to coalesce at many locations (e.g., Fig. 5: outlined in red). Landslides also connected with streams at their feet and thus expanded (e.g., Fig. 5: outlined in blue). The slip surfaces of landslides predominantly formed near the bottoms of layers consisting of volcanic ash and pumice from the Tarumae volcano (Ta-d), which was deposited at about 


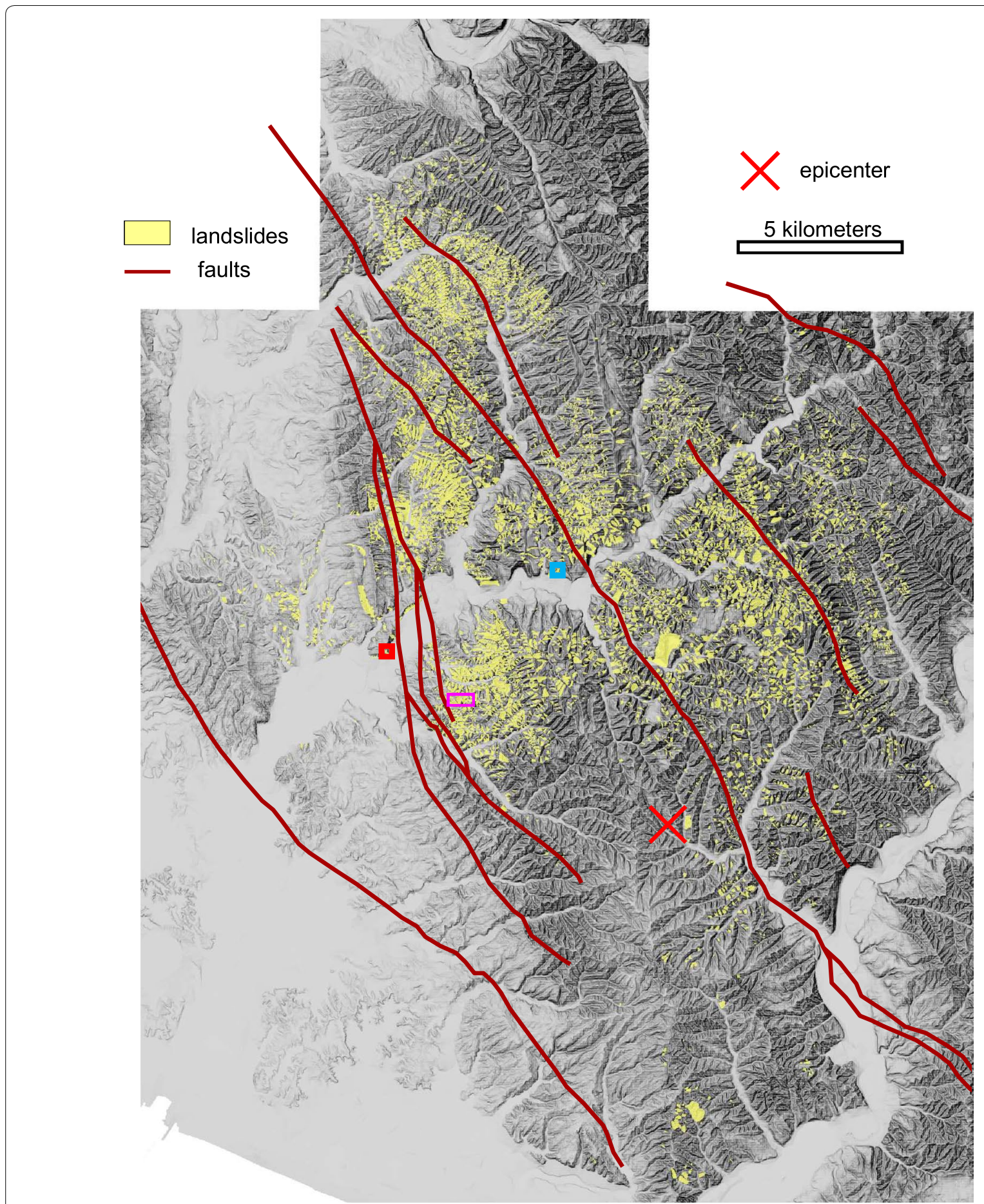

Fig. 3 Distribution of landslides induced by the Hokkaido Eastern Iburi Earthquake in 2018. Fault locations are based on a 1:200,000 land geological map of the Ishikari Depression and its surrounding area, provided by Ozaki et al. (2014). Landslides were identified by Kita (2018). Pink square: area shown in Fig. 5; Red square: location of a photographic image presented in Fig. 6; Blue square: location of soil stratification demonstrated in Fig. 7

9,000 ybp (Yanai 1989; Nakagawa et al. 2018). Figure 6 is a photograph of a landmass that slipped over the base of Ta-d layer (orange-brown) on the slope. These layers usually occur a few to several meters below the ground surface (Figs. 6, 7) on most slopes, except those steeper than $35^{\circ}$ (Osanai et al. 2019). The natural water content 


\section{0

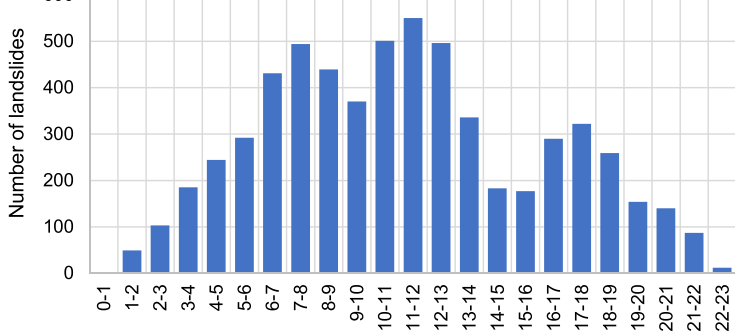 Distance from the epicenter $(\mathrm{km})$}

Fig. 4 Number of landslides and horizontal distances from the epicenter. Distances were measured by setting concentric circles with radii $1 \mathrm{~km}$ apart, originating at the epicenter

of soil samples from the upper and middle parts of Ta-d layer, collected 1 week after the earthquake, on September 13 , was 99.9 and $137.7 \%$, respectively. The locations of sampling holes are marked by blue (upper part) and white (middle part) circles in Fig. 7. On the day of sampling, Ta-d layers were very saturated; water sprang out in some places on exposed slip surfaces, although conditions were not damp before the earthquake: $6 \mathrm{~mm} /$ day and $2.5 \mathrm{~mm} / \mathrm{h}$ at maximum on August 30; $10.5 \mathrm{~mm} /$ day and $7 \mathrm{~mm} / \mathrm{h}$ at maximum on August 31; and $12 \mathrm{~mm} /$ day and $9 \mathrm{~mm} / \mathrm{h}$ at maximum on September 5 at the Japanese Meteorological Agency Atsuma observatory station (Fig. 1). In total, only $7 \mathrm{~mm}$ of rainfall was recorded between the earthquake and September 13. The grain size distribution of the samples collected from the locations marked in Fig. 7 is presented in Fig. 8. The liquid and plastic limits for the same sample collected from the upper part were 149.9 and $96.8 \%$, respectively, and 184.9 and $113.3 \%$ for the one from the middle part. Slip surfaces of shallow landslides also formed in other tephra layers, such as En-a (Osanai et al. 2019). Andosol contained decomposed tephra, and weathered mudrock too composed slip surfaces (Osanai et al. 2019). Additionally, the layer of the one deep-seated rockslide that created a landslide dam may have been in shattered mudrock, although further investigation is needed for confirmation.

\section{Methods}

A publicly available landslide inventory created by Kita (2018) (https://github.com/koukita/2018_09_06_atuma tyou) was used in this study. This inventory was based on bare land detected on orthophotographs taken from 6 to 11 September by the Geospatial Information Authority of Japan (GSI). Despite the good resolution of the image, clouds hid $0.5 \mathrm{~km}^{2}$ of the area, and shadow created by trees and ground relief made it difficult to identify the outlines of landslides in some locations. In fact, the other inventory produced by GSI from the same image, which is also available on the internet (https://saigai.gsi.go.jp/3/20180906/iburi -hokai_2-zentaizu.pdf), demonstrates a very similar but somewhat different distribution and area of landslides from the inventory provided by Kita. Nevertheless, the total landslide area of the GSI inventory was $48.4 \mathrm{~km}^{2}$, according to the author's estimates from the

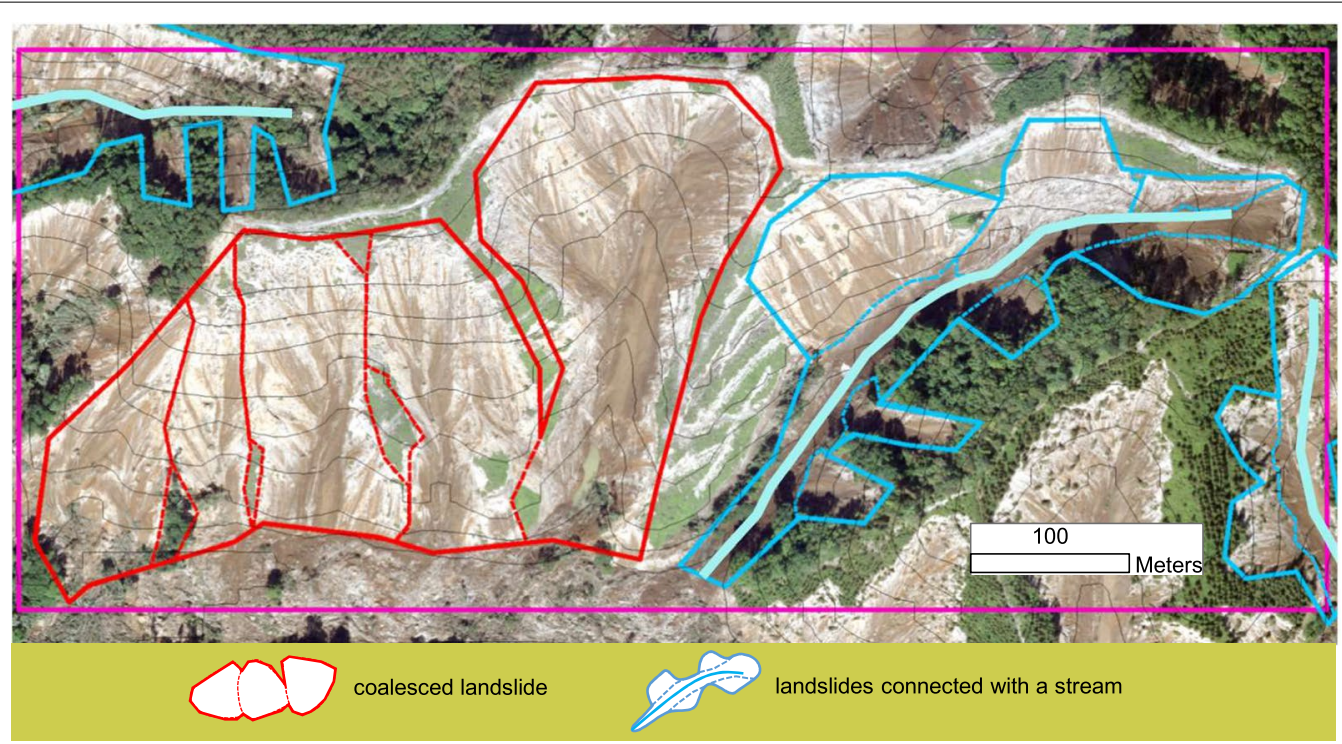

Fig. 5 Enlarged image of the area framed in pink in Fig. 3. Dashed lines divide individual identified landslides. Streams connected with landslides are indicated by pale blue lines. The contour interval is $10 \mathrm{~m}$. The original inventory was produced by Kita (2018). This photograph was provided by the Hokkaido Regional Development Bureau 


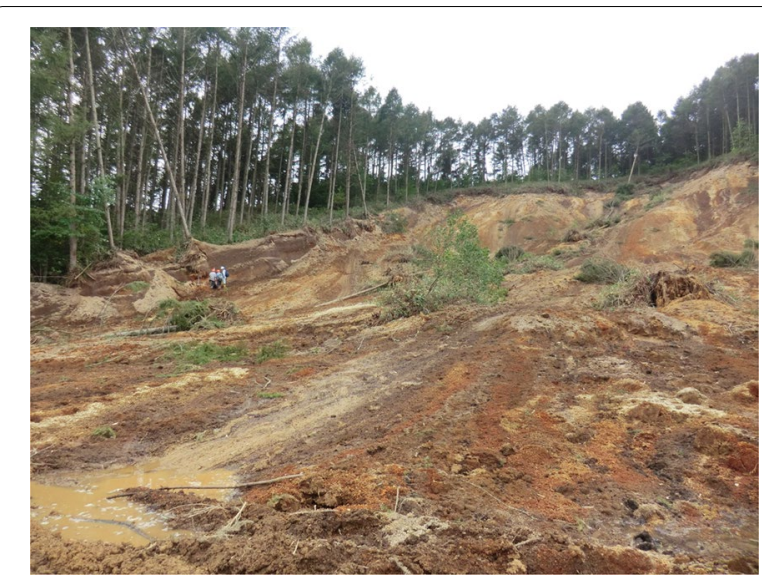

Fig. 6 A photographic image of a landslide, taken on the day after the earthquake at the location marked by a red square in Fig. 3. The base of Ta-d layer (orange-brown) was exposed over the landslide scar, indicating the location of a slip surface

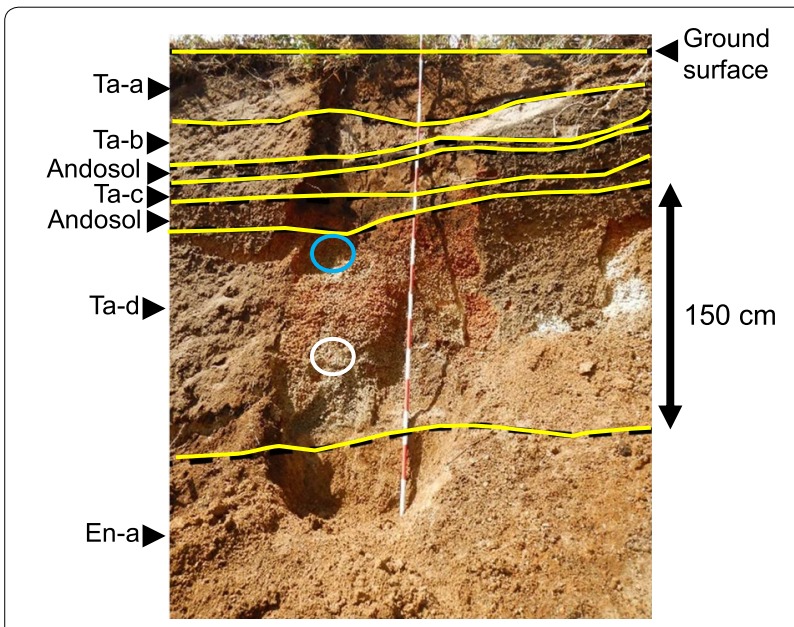

Fig. 7 An example of soil stratification at the location marked by a blue square in Fig. 1. Ta: tephra produced by the Tarumae volcano. a in 1739, b in 1667, c at 2500 ybp, and $\mathbf{d}$ at 9000 ybp. En-a: tephra produced by the Eniwa volcano at 20,000 ybp (Nakagawa et al. 2018). Blue and white circles show the locations of soil sampling

inventory map, showing good agreement with the 43.8 $\mathrm{km}^{2}$ of the Kita (2018) inventory, considering that the former contains more landslide deposition area on the plain than the latter. The size of each landslide was obtained based on landslide polygons provided by Kita using ArcGIS software. The total number of landslides in the Kita (2018) inventory was 6117, and the average size was $7160 \mathrm{~m}^{2}$, more than twice the $3070 \mathrm{~m}^{2}$ demonstrated by Malamud et al. (2004), reflecting coalesced and expanded features of landslides unique to the area.

The slope angle and curvature of the study area were calculated with a $10 \mathrm{~m}$ digital elevation model (DEM)

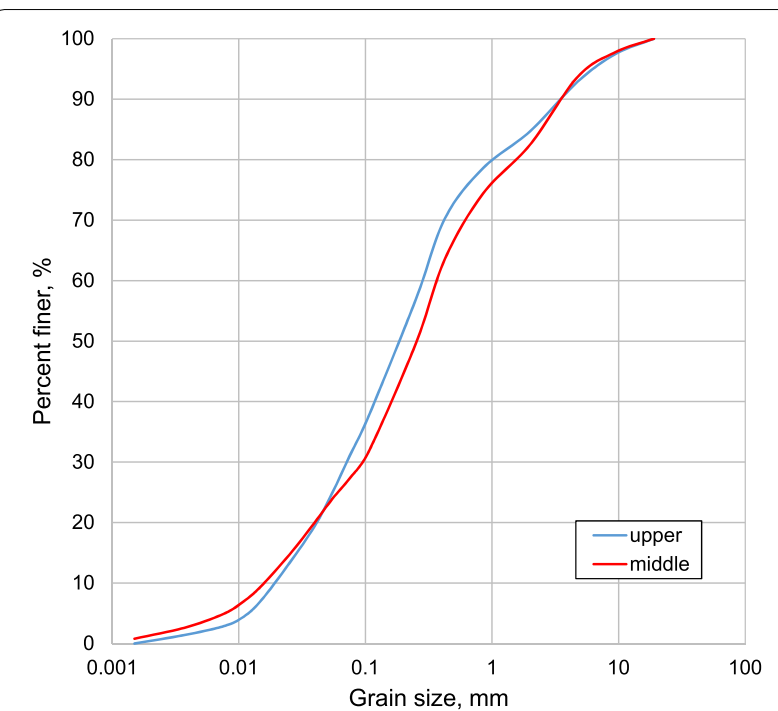

Fig. 8 Grain size distribution of Ta-d soil samples. Upper: sample collected from the upper part of the layer; Middle: sample collected from the middle part of the layer. Both the sampling locations were marked in Fig. 7

using ArcGIS software, made available to the public by GSI (https://www.gsi.go.jp/kiban/index.html; index numbers: 6341-77, 6441-07, 6441-17, 6442-00, 6442$10)$. Because this DEM set was produced from a contour map with a scale of 1:25,000 and error up to $5 \mathrm{~m}$, a certain degree of uncertainty had to be considered when using the data. Hence, this study used the averaged value for slope angle, as well as the profile and planform curvature of $10-\mathrm{m}$ cells contained in a landslide polygon, to represent its topographic characters. With the averaged curvature, each landslide was classified into four types: Cc, concave for profile and planform curvature; Ccpr, concave for profile and convex for planform curvature; $\mathrm{Ccpl}$, concave for planform and convex for profile curvature; and $\mathrm{Cv}$, convex for both curvatures (Fig. 9). This study neglected the degree of curvature, and 'planer' surface was not considered because of the data uncertainty mentioned above.

Following Malamud et al. (2004), the probability-size distribution of landslides in the study area was given by:

$$
p\left(A_{L}\right)=\frac{1}{N_{\mathrm{LT}}} \frac{\delta N_{L}}{\delta A_{L}},
$$

where $p\left(A_{L}\right)$ is a probability density function, $\delta \mathrm{N}_{\mathrm{L}}$ is the number of landslides with areas between $A_{L}\left(\mathrm{~km}^{2}\right)$ and $\mathrm{A}_{\mathrm{L}}+\delta \mathrm{A}_{\mathrm{L}}$, and $\delta \mathrm{A}_{\mathrm{L}}\left(\mathrm{km}^{2}\right)$ is based on the log scale. The frequency density of landslides, $\left(\mathrm{A}_{\mathrm{L}}\right)$, is given by:

$$
f\left(A_{L}\right)=N_{\mathrm{LT}} p\left(A_{L}\right)
$$




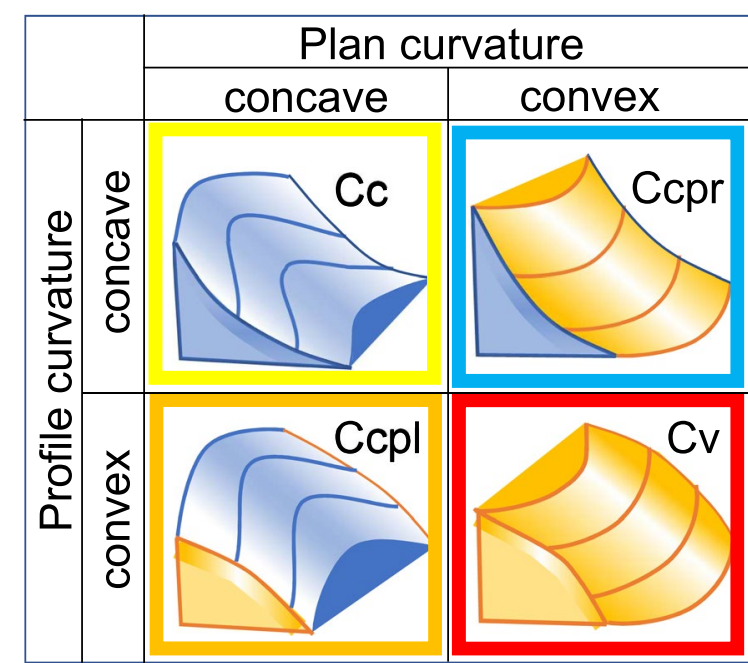

Fig. 9 Schematic diagram of slope types classified based on the profile and planform curvatures of each landslide

where $N_{\mathrm{LT}}$ is the total number of landslides in an inventory. This study defined rollover as the smallest value at which the best coefficient of determination was obtained for power law decay.

The frequency-size distribution of landslides in the study area was compared with those for various event magnitudes proposed by Malamud et al. (2004), to assess the nature of this landslide event. They represented the probability density of landslides with area $A_{L}\left(\mathrm{~km}^{2}\right)$ as follows:

$$
p\left(A_{L}: \rho, a, s\right)=\frac{1}{a \Gamma(\rho)}\left[\frac{a}{A_{L}-s}\right]^{\rho+1} \exp \left[-\frac{a}{A_{L}-s}\right]
$$

where $\rho$ is a parameter controlling the power law decay for medium and large landslides, $a\left(\mathrm{~km}^{2}\right)$ is a parameter controlling the location of the maximum probability distribution, $s\left(\mathrm{~km}^{2}\right)$ is a parameter controlling the exponential rollover for small landslides, and $\Gamma(\rho)$ is the gamma function of $\rho$. According to the analysis by Malamud et al. (2004), we adopt $\rho=1.40, a=1.28 \times 10^{-3} \mathrm{~km}^{2}$, $s=-1.32 \times 10^{-4} \mathrm{~km}^{2}$, and $\Gamma(1.4)=0.88726$. Malamud et al. (2004) also proposed a magnitude scale for a landslide event, $m_{L}$, as follows:

$$
m_{L}=\log _{10}\left(N_{\mathrm{LT}}\right) .
$$

The combination of Eqs. (1)-(4) provides the frequency density of landslides linked to the magnitude scale of a landslide event. A list of symbols describing the key parameters of the area and the inventory is provided in Table 1.
Table 1 Symbol descriptions

\begin{tabular}{ll}
\hline Symbol & Description \\
\hline$A$ & Area of landslide distribution induced by earthquakes $\left(\mathrm{km}^{2}\right)$ \\
$A_{L}$ & Landslide area $\left(\mathrm{km}^{2}\right)$ \\
$A_{\mathrm{LT}}$ & Total area of landslides in an inventory $\left(\mathrm{km}^{2}\right)$ \\
$N_{\mathrm{LT}}$ & Total number of landslides in an inventory \\
$m_{L}$ & A magnitude scale for a landslide event $\left(=\log 10\left(N_{\mathrm{LT}}\right)\right)$
\end{tabular}

\section{Results and discussion}

\section{Topographic characteristics of landslides}

The average slope angle of the landslides induced by the earthquake was $27.1^{\circ}$, with a standard deviation of 6.4. They were generally steeper in the eastern part of the study area, reflecting the landscape (Figs. 1, 10). The probability density was highest in the range of $25^{\circ}-30^{\circ}$ of average slope (Fig. 11). Some landslides were very gentle, with an average angle of less than $20^{\circ}$ (Figs. 10, 11), implying that this event was largely influenced by soil properties. Landslide size tended to increase as slope angle increased up to $20^{\circ}-25^{\circ}$ and then decreased with further increase of slope angle (Fig. 12). There were nine landslides larger than $10^{-1} \mathrm{~km}^{2}$, and their slope angle was between $20^{\circ}$ and $30^{\circ}$ (Figs. 10, 12: outlined in pink in Fig. 10). The deep-seated rockslide that formed a landslide dam (white arrow in Fig. 10) was the largest of these, at $5.4 \times 10^{-1} \mathrm{~km}^{2}$, and its slope angle was $21.7^{\circ}$. Other than this slide, there were coalesced landslides over low divides between catchments and at streams, mainly located in the western part of the study area (Fig. 10b). Although coalesced landslides could be found in the eastern part, the results indicate that gentler landscape provides more opportunities for individual landslides to unite and enlarge. In addition, although steeper slopes are generally less stable, Fig. 12 implies that these slopes do not hold materials that could move as landslides, because the ground is too steep, as exemplified by the Ta-d layer missing on slopes greater than $35^{\circ}$.

As for slope curvature, $48 \%$ of the landslides were classified as the Cc type, and these were found over the entire study area (Fig. 13). Among the nine landslides larger than $10^{-1} \mathrm{~km}^{2}$, seven belonged to the Cc type and two were of the Ccpr type; one of these was the largest slide mentioned above. According to Student's t-test, the average landslide size differed significantly between slope types, except between the $\mathrm{Ccpr}$ and $\mathrm{Cv}$ types and between the Ccpr and Ccpl types. The average and median landslide sizes of the Cc type were the largest, at 8720 and $4980 \mathrm{~m}^{2}$, whereas those of Cv type, which occupied $17 \%$ of all the landslides and tended to appear in the eastern part of the area, were the smallest, at 5190 and $2710 \mathrm{~m}^{2}$, respectively (Fig. 14). The average and median 


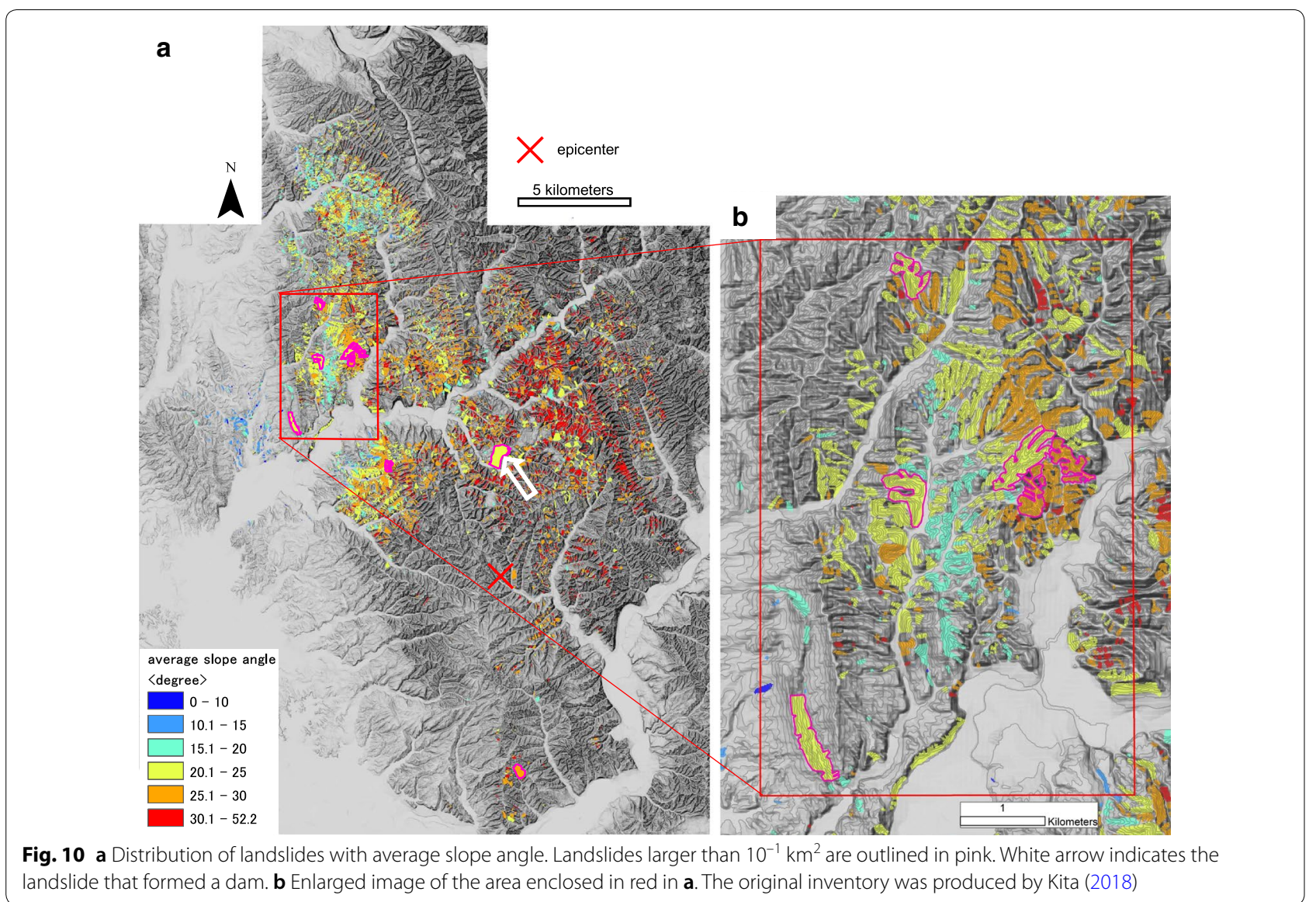

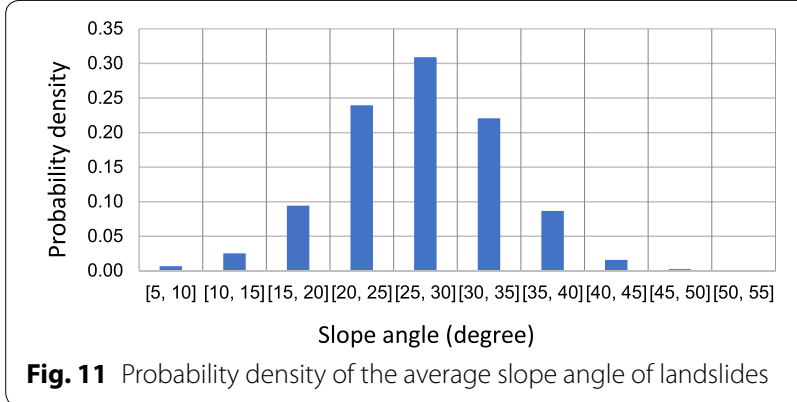

sizes of the remaining slope types, Ccpl (17\% of all landslides) and Ccpr (18\%), were between the values of the Cc and $\mathrm{Cv}$ types, but the former had larger sizes.

Additional field data will be collected to underpin our assumption regarding the relationship of slope angle and curvature with soil thickness and groundwater level. Nevertheless, the results suggest that the assumption was not contradicted by the outcomes and that these topographic features can be regarded as major factors controlling landslide sizes in this environment. Further topographic analyses were not conducted because of

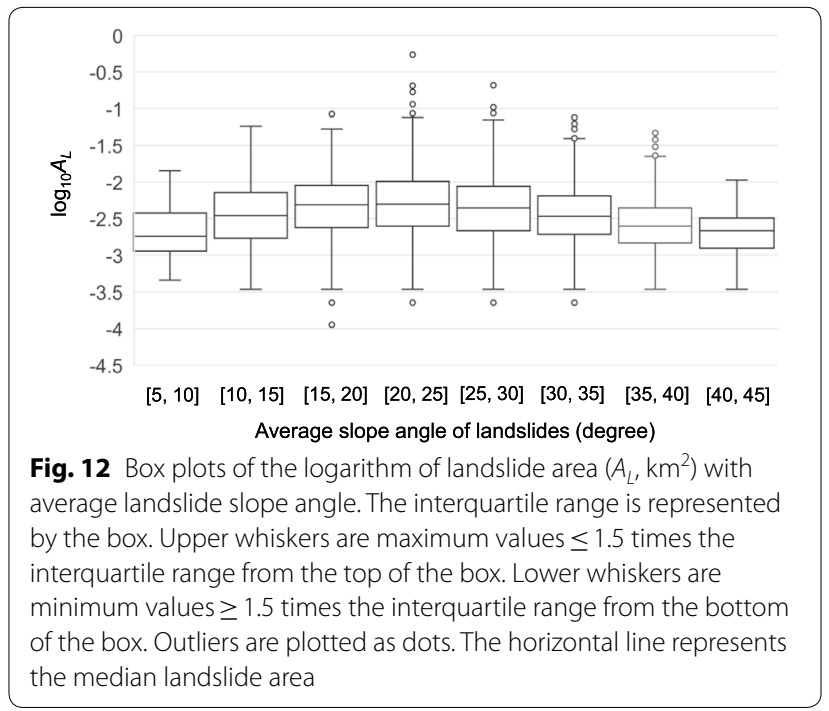

uncertainty in the data and a lack of detailed information regarding landslide types at present. With more precise and detailed topographic data, as well as field information, the classification of slope types could be refined to 


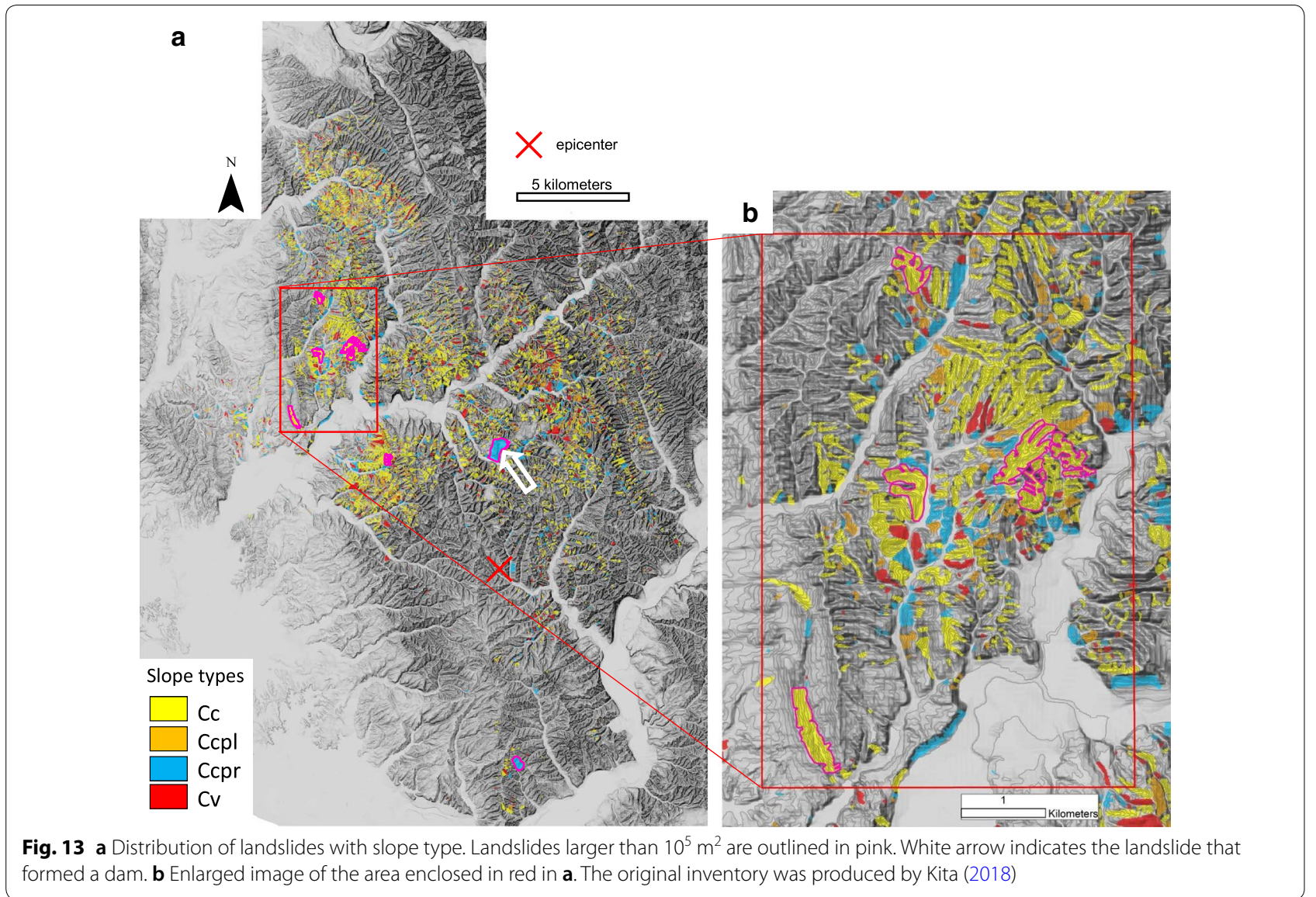

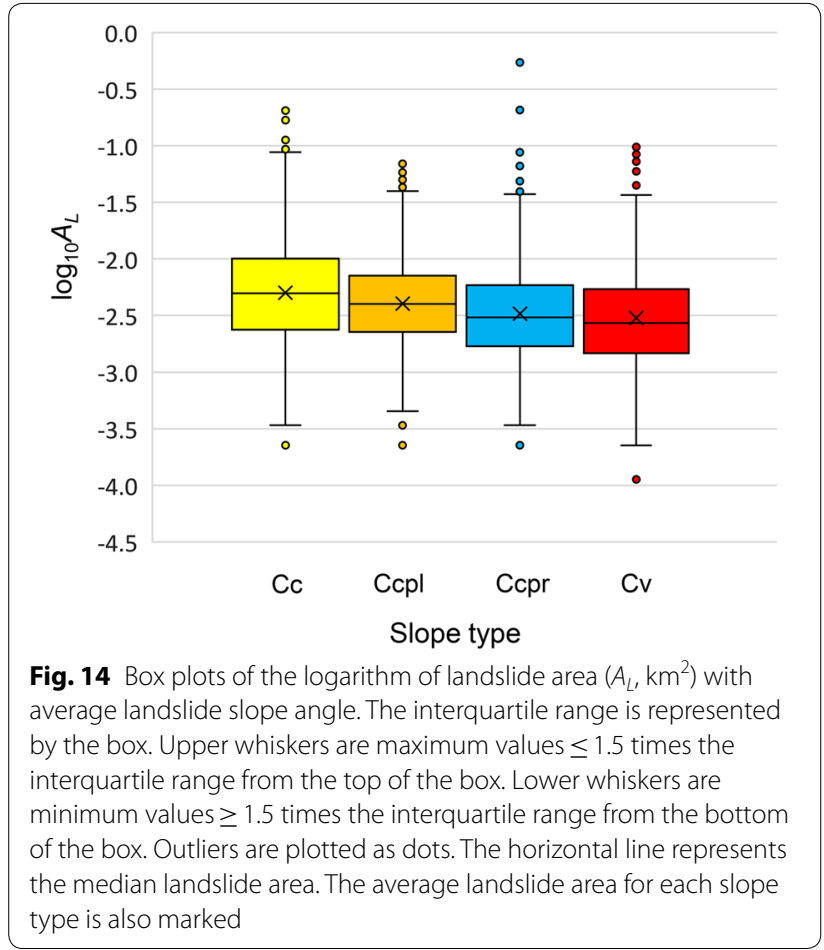

more clearly identify the relationship between slope curvature and landslide size.

\section{Frequency-size distribution of landslides}

Figure 15 presents the frequency-size distribution of the landslides and those provided for each $m_{L}$ drawn with Eqs. (1)-(4). Based on Eq. (4), the $m_{L}$ for this earthquake event is 3.79 , but landslides of medium to large size in the study area fit the distribution curve for $m_{L}$ between 4 and 4.5. The rollover, $5.0 \times 10^{-3} \mathrm{~km}^{2}$, was much larger than the value suggested by the equations, of $4.0 \times 10^{-4} \mathrm{~km}^{2}$ (Fig. 16). Examining the effect of slope curvature on the size distribution, the frequencysize distribution of landslides of each slope type was also plotted on Figs. 15 and 16, revealing that the rollover values of the Cc and Ccpl types were $6.0 \times 10^{-3}$ $\mathrm{km}^{2}$ and that those for the Ccpr and $\mathrm{Cv}$ types were $3.0 \times 10^{-3} \mathrm{~km}^{2}$. The higher rollover for the Cc and Ccpl types may imply that cross-sectional concave features were likely to accumulate more water and soil than the other types, as also shown by the larger median landslide sizes than for the other types. 


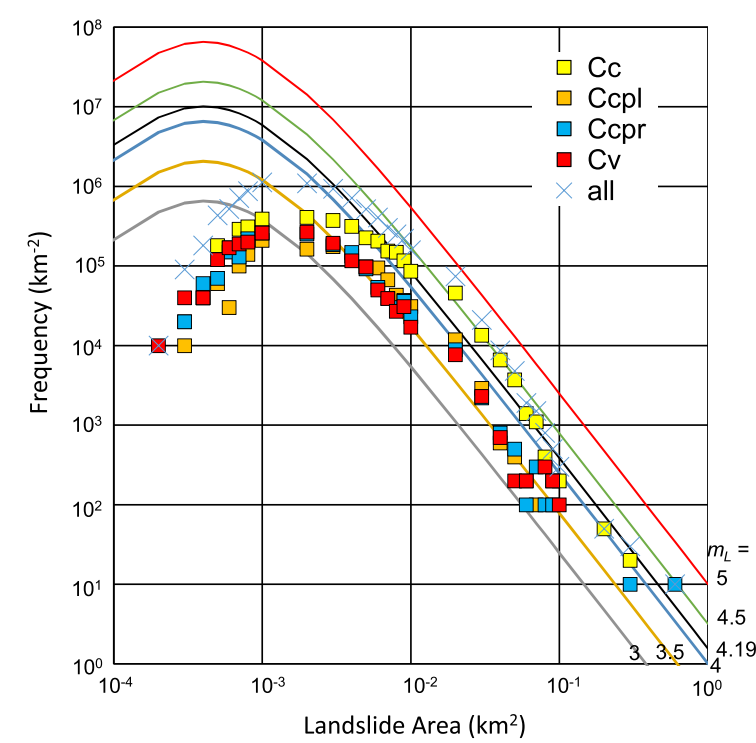

Fig. 15 Frequency-size distribution of landslides for all landslides, and for landslides of each slope type. The distribution curves for $m_{L}$ from 3 to 5 are also shown

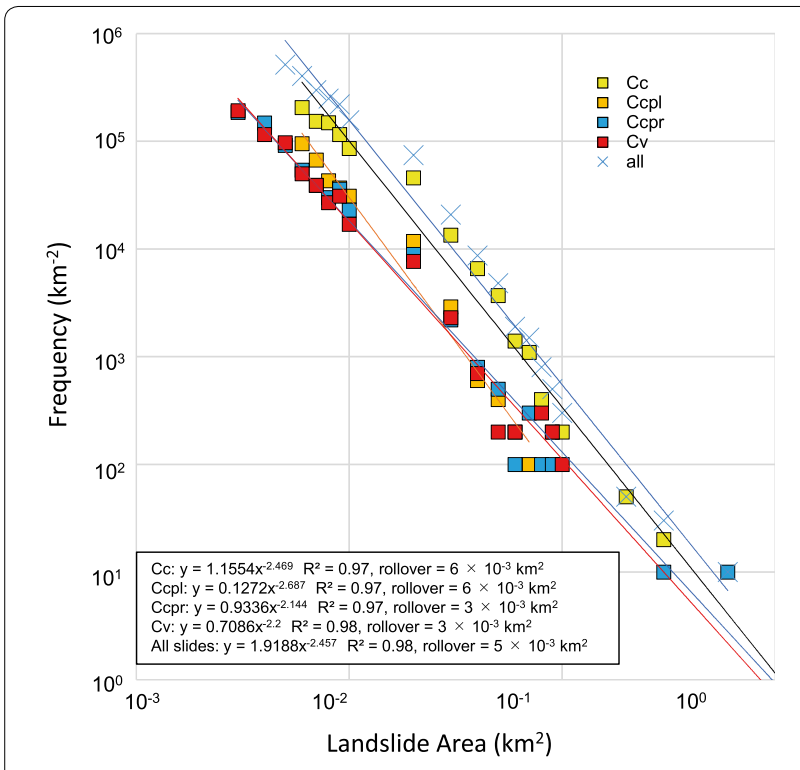

Fig. 16 Frequency-size distribution of landslides for all landslides and each slope type after rollover

Generally, historical landslide inventories demonstrate high rollover due to a lack of small landslides, which often fade with time (Malamud et al. 2004). The low-resolution imagery used to create a landslide inventory may also contribute to this pattern because small landslides cannot be identified on such images (Stark and Hovius 2001; Frattini and Crosta 2013). However, the inventory used for this study was created immediately after the earthquake using high-resolution aerial photographs, in which landslides of $200 \mathrm{~m}^{2}$ were still recognizable. Therefore, rollover in the study area was related to shallow landslides induced in homogeneous and incoherent surface soil, as demonstrated by Katz and Aharonov (2006). The high rollover value can largely be attributed to soil properties because the layers, particularly Ta- $d$, were presumed to be vulnerable to ground shaking, and thus reduced cohesion, due to constant saturation, demonstrated by the soil samples collected within 1 week after the earthquake and the weather around the sampling date. The gentle landscape and limited slope length also contributed to high rollover by allowing adjacent landslides to merge together over ridges or at streams. In the study area, coalesced landslides mainly determined the power law decay for medium to large slides, whereas Katz and Aharonov (2006) demonstrated that heterogeneous rock mass played this role for deeper landslides. Nevertheless, the exponent of the power law decay for all landslides was -2.46 , and those for each slope type were from -2.69 to -2.14 (Fig. 16), within the range demonstrated by Van Den Eeckhaut et al. (2007) in their historical and eventtriggered landslide inventories $(-2.3 \pm 0.6)$.

\section{Comparison of the landslide event caused by the Hokkaido} Eastern Iburi Earthquake with other seismic cases

The landslide event induced by the Hokkaido Eastern Iburi Earthquake was compared with other seismically triggered cases to characterize the event. Regarding the area of landslide distribution induced by earthquakes, $A\left(\mathrm{~km}^{2}\right)$, Keefer and Wilson (1989) presented a linear regression relationship with moment magnitude, $M_{w}$, as follows:

$$
\log 10 A=M_{w}-3.46( \pm 0.47) .
$$

With $M_{w}=6.6$, Eq. (5) gives $A$ ranging from 470 to 4070 $\mathrm{km}^{2}$, and the study area plots are near the low end of the range. For the number of seismically caused landslides, $N_{\text {LT }}$, Keefer (2002) presented the following empirical relationship:

$$
\log 10 N_{\mathrm{LT}}=1.2312 M_{w}-4.8276\left(R^{2}=0.72\right) .
$$

Thus, for $M_{w}=6.6, N_{\mathrm{LT}}$ is 1988. In turn, inserting $N_{\mathrm{LT}}=6117$ into Eq. (6), $M_{w}=7.0$. The relationship between $M_{w}$ and $N_{\mathrm{LT}}$ for the 11 cases from Keefer (2002), six published cases (Wang et al. 2002; Dai et al. 2011; Alfaro et al. 2012; Xu and Xu 2014; Xu et al. 2015; Roback et al. 2018), and the result of this study (Fig. 17) yields a slightly different equation from Eq. (6), as shown below:

$$
\log 10 N_{\mathrm{LT}}=0.9842 M_{w}-3.1174\left(R^{2}=0.69\right) .
$$

With Eq. (7), $M_{w}=6.6$ yields an $N_{\mathrm{LT}}$ of 2,390, and an $N_{\mathrm{LT}}$ of 6117 provides $M_{w}=7.0$. Xu et al. (2015) 


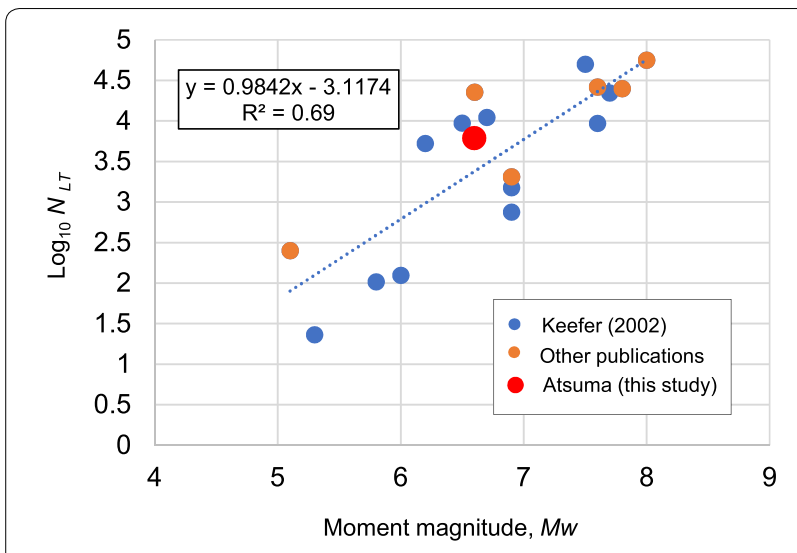

Fig. 17 Relationship between moment magnitude $\left(M_{w}\right)$ and total number of landslides $\left(N_{L T}\right)$ for 11 cases from Keefer (2002), six other published cases (Wang et al. 2002; Dai et al. 2011; Alfaro et al. 2012; Xu and Xu 2014; Xu et al. 2015; Roback et al. 2018), and the current study

demonstrated a relationship between total landslide area, $A_{\mathrm{LT}}$, and moment magnitude with 13 earthquake events:

$$
A_{\mathrm{LT}}=9 \times 10^{-7} \exp \left(2.4585 M_{w}\right)\left(R^{2}=0.69\right) .
$$

In the above, with $M_{w}=6.6, A_{\mathrm{LT}}$ is $10.0 \mathrm{~km}^{2}$. Malamud et al. (2004) also presented a relationship between $m_{L}$ and $\log _{10} A_{\mathrm{LT}}$, given by:

$$
m_{L}=\log 10 A_{\mathrm{LT}}+2.51 \text {. }
$$

Combining Eqs. (4) and (9), $A_{\mathrm{LT}}$ becomes $18.9 \mathrm{~km}^{2}$ with $N_{\mathrm{LT}}=6117$. Conversely, by applying $A_{\mathrm{LT}}=43.8 \mathrm{~km}^{2}$ to Eq. (9), $m_{L}$ becomes 4.19 , and then, with Eqs. (4) and (6), $M_{w}$ becomes 7.4. For the order of magnitude, $A_{\mathrm{LT}}=43.8$ $\mathrm{km}^{2}$ is not far from the values estimated from the equations. However, all of the values given above suggest that the landslides triggered by the Hokkaido Eastern Iburi Earthquake can be characterized as more clustered, more numerous, and covering a larger area for the moment magnitude of the earthquake than the 'average' of seismically induced events. The values also indicate that the event was equivalent to an event caused by an earthquake of $M_{w}=7.0$ to 7.4 . With an occupancy of $11 \%$ of the land by landslides, this moment magnitude does not appear to be extreme. As the model by Liucci et al. (2017) suggested that the intensity of an event controls the probability distribution of landslide size, the strong seismic intensity and peak ground acceleration of the Hokkaido Eastern Iburi Earthquake probably contributed to producing high rollover, together with soil layers that were very sensitive to ground shaking and the topographic characteristics of the study area. Unfortunately, this study did not address this issue further because of the limited availability of detailed information about the intensity. As mechanisms such as fault plane motion become clearer with time, understanding of this landslide event will improve, which should contribute to appraising the magnitude of future landslide events globally and finding an empirical relationship between intensity and event magnitude, similar to those with moment magnitude.

\section{Conclusion}

Gently undulating regions other than those prone to deep-seated landslides are usually paid scant attention for landslide hazards, even though there is a historic record of seismically induced landslides. This is mainly because rainfall rarely triggers landslides due to the gentle slope angle. The occurrence of a landslide event in the study area is not frequent, possibly once every few thousands of years, considering that similar seismic events occurred between 4600 and 2500 ybp (Tajika et al. 2016). In fact, the almost undisturbed soil stratigraphy exposed in many landslide scars indicates that those slopes had been stable for more than $9000 \mathrm{ybp}$. The results suggest that the combination of low-elevation relief and volcanic soil, which can move very easily in response to ground shaking, may cause unexpectedly large numbers and sizes of landslides when the area is struck by an intense earthquake. In this case, concave slopes are more prone to landslides, which tend to be larger than those on convex slopes.

The frequency-size distribution of landslides in the study area indicated that the magnitude scale for the landslide event, $m_{L}$, was equivalent to that of an area struck by an earthquake of $M_{w}=7.0$ to 7.4 with high rollover. Finding the rollover and the exponent of power law decay will considerably facilitate landslide hazard assessment. This study demonstrated that slope angle and curvature were associated with the size distribution, that is, rollover, whereas the exponent of power law decay, -2.3 , appeared to be similar to those of past case studies and applicable to any location. Efforts to identify ways to predict the rollover associated with earthquake intensity will be furthered by building models, performing laboratory experiments, and collecting field cases, with consideration given to the mechanics of slope mass movement and the degree of topographic restriction. A series of works will contribute to reducing landslide disaster globally in the future.

\section{Abbreviations}

USGS: U.S. Geological Survey; GSI: Geospatial Information Authority of Japan; NIED: National Research Institute for Earth Science and Disaster Resilience, Japan.

\section{Acknowledgements}

We appreciate the financial support (Project Number 18K19952) from the ministry of Education, Culture, Sports, Science and Technology. Two anonymous reviewers are thanked for their constructive comments to greatly improve this manuscript. 


\section{Authors' contributions}

MK designed this work, analyzed topographic data on GIS and has drafted the work mainly. TY acquired field data, analyzed it, and helped completing the manuscript. Both authors read and approved the final manuscript.

\section{Funding}

18K19952, Grant-in-Aid for Special Purposes, The ministry of Education, Culture, Sports, Science and Technology.

\section{Availability of data and materials}

The datasets supporting the conclusions of this article are available in the figshare repository: https://doi.org/10.6084/m9.figshare.9567008.

\section{Ethics approval and consent to participate}

Not applicable.

\section{Consent for publication}

Not applicable.

\section{Competing interests}

The authors declare that they have no competing interests.

Received: 18 February 2019 Accepted: 6 August 2019

Published online: 17 August 2019

\section{References}

Alfaro P, Delgado J, García-Tortosa FJ et al (2012) Widespread landslides induced by the Mw 5.1 earthquake of 11, May 2011 in Lorca. SE Spain Eng Geol. https://doi.org/10.1016/j.enggeo.2012.04.002

Dai FC, Xu C, Yao X et al (2011) Spatial distribution of landslides triggered by the 2008 Ms 8.0 Wenchuan earthquake. China. J Asian Earth Sci. https:// doi.org/10.1016/j.jseaes.2010.04.010

Frattini P, Crosta GB (2013) The role of material properties and landscape morphology on landslide size distributions. Earth Planet Sci Lett. https:// doi.org/10.1016/j.epsl.2012.10.029

Katz O, Aharonov E (2006) Landslides in vibrating sand box: What controls types of slope failure and frequency magnitude relations? Earth Planet Sci Lett. https://doi.org/10.1016/j.epsl.2006.05.009

Keefer DK (2002) Investigating landslides caused by earthquakes - a historical review. Surv Geophys. https://doi.org/10.1023/A:1021274710840

Keefer DK (1994) The importance of earthquake-induced landslides to longterm slope erosion and slope-failure hazards in seismically active regions. Geomorphology. https://doi.org/10.1016/0169-555X(94)90021-3

Keefer DK, Wilson RC (1989) Predicting earthquake-induced landslides, with emphasis on arid and semi-arid environments. Landslides a semi-arid Environ 2:118-149

Kita K (2018) An inventory of landslides triggered by Hokkaido Eastern Iburi earthquake, September 2018. https://www.gsi.go.jp/kikakuchousei/kikak uchousei40182.html. Accessed 20 Dec 2018

Korup O, Clague JJ, Hermanns RL et al (2007) Giant landslides, topography, and erosion. Earth Planet Sci Lett. https://doi.org/10.1016/j.epsl.2007.07.025

Liucci L, Melelli L, Suteanu C, Ponziani F (2017) The role of topography in the scaling distribution of landslide areas: A cellular automata modeling approach. Geomorphology. https://doi.org/10.1016/j.geomo rph.2017.04.017
Malamud BD, Turcotte DL, Guzzetti F, Reichenbach P (2004) Landslide inventories and their statistical properties. Earth Surf Process Landforms. https:// doi.org/10.1002/esp.1064

Nakagawa M, Amma-Miyasaka M, Miura D, Uesawa S (2018) Tephrostratigraphy in Ishikari Lowland, Southwestern Hokkaido: Eruption history of the Shikotsu-Toya volcanic field. J Geol Soc Japan 124:473-489. https://doi. org/10.5575/geosoc.2018.0038 (in Japanese with English abstract and figure captions)

Osanai N, Kaibori M, Yamada T et al (2019) Sediment-related disasters induced by the 2018 Hokkaido Eastern Iburi Earthquake. J Eros Control Eng 71:54-65 (in Japanese with English abstract)

Ozaki M, Komatsubara T, Geological Survey of Japan AIST (2014) 1:200,000 land geological map of the Ishikari Depression and its surrounding area. https ://www.gsj.jp/data/coastal-geology/GSJ_SGMCZ_S4_2014_03_a.pdf. Accessed 20 Dec 2018

Pelletier JD, Malamud BD, Blodgett T, Turcotte DL (1997) Scale-invariance of soil moisture variability and its implications for the frequency-size distribution of landslides. Eng Geol 48:255-268. https://doi.org/10.1016/ S0013-7952(97)00041-0

Qiu H, Cui P, Regmi AD et al (2018) The effects of slope length and slope gradient on the size distributions of loess slides: field observations and simulations. Geomorphology. https://doi.org/10.1016/j.geomorph.2017.10.020

Roback K, Clark MK, West AJ et al (2018) The size, distribution, and mobility of landslides caused by the 2015 Mw7.8 Gorkha earthquake, Nepal. Geomorphology. https://doi.org/10.1016/j.geomorph.2017.01.030

Rodríguez CE, Bommer JJ, Chandler RJ (1999) Earthquake-induced landslides: 1980-1997. Soil Dyn Earthq Eng. https://doi.org/10.1016/S0267 $-7261(99) 00012-3$

Stark CP, Hovius N (2001) The characterization of landslide size distributions. Geophys Res Lett. https://doi.org/10.1029/2000GL008527

Tajika J, Ohtsu S, Inui T (2016) Interior structure and sliding process of landslide body composed of stratified pyroclastic fall deposits at the Apporo 1 archaeological site, southeastern margin of the Ishikari Lowland, Hokkaido, Noth Japan. Jour Geol Soc Japan 122:23-35. https://doi. org/10.5575/geosoc.2015.0037 (in Japanese with English abstract and figure captions)

Van Den Eeckhaut M, Poesen J, Govers G et al (2007) Characteristics of the size distribution of recent and historical landslides in a populated hilly region. Earth Planet Sci Lett. https://doi.org/10.1016/j.epsl.2007.01.040

Wang WN, Nakamura H, Tsuchiya S, Chen CC (2002) Distributions of landslides triggered by the Chi-chi Earthquake in Central Taiwan on September 21, 1999. Landslides 38:318-326. https://doi.org/10.3313/jls1964.38.4 318

Xu C, Xu X (2014) Statistical analysis of landslides caused by the Mw 6.9 Yushu, China, earthquake of April 14, 2010. Nat Hazards. https://doi.org/10.1007/ s11069-014-1038-2

Xu C, Xu X, Shyu JBH (2015) Database and spatial distribution of landslides triggered by the Lushan, China Mw 6.6 earthquake of 20 April 2013. Geomorphology. https://doi.org/10.1016/j.geomorph.2015.07.002

Yanai S (1989) Age determination of hillslope with tephrochronological method in central Hokkaido, Japan. Trans Japanese Geomorphol Union 10:1-12 (in Japanese with English abstract and figure captions)

\section{Publisher's Note}

Springer Nature remains neutral with regard to jurisdictional claims in published maps and institutional affiliations. 